\section{Clinicopathological study and outcomes of primary extranodal lymphoma}

\author{
Nichapa Nanthakwang, ${ }^{1}$ \\ Ekarat Rattarittamrong, 1 \\ Thanawat Rattanathammethee, ${ }^{1}$ \\ Chatree Chai-Adisaksopha, ${ }^{1}$ \\ Adisak Tantiworawit, ${ }^{1}$ \\ Lalita Norrasethada, ${ }^{1}$ Charin Ya-In ${ }^{2}$ \\ ${ }^{1}$ Department of Internal Medicine and \\ ${ }^{2}$ Department of Pathology, Faculty of \\ Medicine, Chiang Mai University, \\ Chiang Mai, Thailand
}

\begin{abstract}
Lymphoma can present with either lymphadenopathy or extranodal involvement. There are limited clinicopathological data pertaining to the occurrence of primary extranodal lymphoma (pENL) in Thailand. This was a retrospective study conducted at Chiang-Mai University Hospital from 2012 to 2016. Patients 18 years of age and over and with a diagnosis of $\mathrm{pENL}$ were enrolled onto study. Data related to clinical presentations, histology, stage, treatment and response were collected. There were 104 pENL patients with a median age of 63 years included. The most common presentation was gastrointestinal symptoms (41\%), followed by ear, nose, and throat symptoms (35\%). Diffuse large B-cell lymphoma (DLBCL) was the most common morphological subtype $(60 \%)$, followed by marginal zone lymphoma (15\%). The majority of patients presented with stage II disease $(55 \%)$. The five-year overall survival rate was $71 \%$. The factors associated with mortality were hemoglobin $<7 \mathrm{~g} / \mathrm{dL}$, B-symptoms and LDH above upper normal limits. This study illustrated that lymphoma can present at various extranodal sites. Gastrointestinal symptoms were the most common presentations and DLBCL was the most common subtype of pENL.
\end{abstract}

\section{Introduction}

Lymphoma is the most common hematologic malignancy and ranks as the seventh most common form of cancer. ${ }^{1}$ The majority of cases are non-Hodgkin's lymphoma (NHL) in particular B-cell lymphoma. ${ }^{2}$ In the World Cancer Report 2014 the estimated incidence of NHL was 6.0 and 4.1 per 100,000 in males and females, respectively. ${ }^{3}$ Although a common presentation of lymphoma is lymphadenopathy, ${ }^{4}$ some patients present with symptoms of extranodal involvement including the gastrointestinal (GI), neurological, and dermatological systems which may lead to a delay in diagnosis and treatment. ${ }^{5}$

A review of relevant literature resulted in the collection of data from various countries about epidemiology, clinical manifestations, pathological results, and treatment outcomes related to extranodal lymphoma. The population-based NHL registry from the Netherlands showed 34\% (389/1168) of NHL patients were classified as primary extranodal NHL (pENL) defined by presentation in other tissues and organs than the lymph nodes, including Waldeyer's ring, spleen or bone marrow, without or with only minor lymph node involvement. The prevalence decreased to $20 \%$ if patients with disseminated disease presenting in an extranodal site were excluded. ${ }^{6}$ A study of 6382 lymphoma patients from Southwest China reported that at diagnosis $53.5 \%$ of all NHL cases presented in extranodal sites since Waldeyer's ring was also included in extranodal sites in this study. ${ }^{7}$ A Dutch study showed that the GI tract was the most common site of pENL $(45.7 \%)^{6}$ whereas it was the second most common site in the Chinese study after Waldeyer's ring (22.3\% and $23.7 \%$ and respectively). ${ }^{7}$ Diffuse large B-cell lymphoma (DLBCL) was the most common histological subtype of pENL in both studies, accounting for $50 \%$ and $42.2 \%$, respectively. ${ }^{6,7}$ However, the second most common subtypes differed in the two studies, with chronic lymphocytic leukemia (CLL)/small lymphocytic lymphoma (SLL) being second in the Dutch study and extranodal NK/T cell lymphoma, nasal type (ENKTL) in the Chinese study. ${ }^{6,7}$ In addition, other studies from Kuwait ${ }^{8}$ and India ${ }^{9}$ showed follicular lymphoma (FL) and marginal zone lymphoma of mucosal associated lymphoid tissue (MALT) respectively accounted for the second highest prevalence after DLBCL.

Investigation into treatment outcomes of pENL, showed no difference in complete response (CR) rates, and overall survival (OS) of pENL and primary nodal NHL in the Netherlands study. ${ }^{6}$ In contrast, the OS of a high-grade lymphoma subgroup of pENL was significantly lower than the nodal high-grade NHL in the study carried out in Kuwait. ${ }^{8}$

Since the epidemiology, clinical presentations, pathology, and outcomes of $\mathrm{pENL}$ differed across studies the primary objective of this study was to gather data regarding clinicopathological features and treatment responses of pENL in Chiang Mai
Correspondence: Ekarat Rattarittamrong, Division of Hematology, Department of Internal Medicine, Faculty of Medicine, Chiang Mai University, Chiang Mai 50200, Thailand

Tel: +66.819296335 -Fax: +66.53935481.

E-mail: ekarat_r@hotmail.com, ekarat.r@cmu.ac.th

Key words: Extranodal lymphoma; Lymphoma; Diffuse large B-cell lymphoma, Marginal zone lymphoma.

Acknowledgments: The authors would like to thank Ms. Antika Wongthani most sincerely for her help in carrying out the statistics in this study.

Contributions: NN designed the research, collected and summarized the clinical data, carried out data analysis, and co-wrote the manuscript; ER designed the research, carried out the data analysis, and co-wrote the manuscript; TR, CC, AT, LN, CY revised the manuscript.

Conflict of interest: The authors declare no potential conflict of interest.

Funding: None.

Received for publication: 30 June 2019.

Revision received: 21 August 2019.

Accepted for publication: 1 October 2019.

This work is licensed under a Creative Commons Attribution-NonCommercial 4.0 International License (CC BY-NC 4.0).

${ }^{\circ}$ Copyright: the Author(s), 2019

Licensee PAGEPress, Italy

Hematology Reports 2019; 11:8227

doi:10.4081/hr.2019.8227

University Hospital in Thailand. The secondary objective was to determine the OS and factors that influence the OS in patients with pENL.

\section{Materials and Methods}

\section{Study overview}

This was a retrospective study conducted in Chiang Mai University Hospital from January 1, 2012 to December 31, 2016. Patients aged $\geq 18$ years who were diagnosed with lymphoma according to the 2008 World Health Organization (WHO) classification ${ }^{10}$ by hematopathologists and had a pENL defined by presentation in extranodal organs (organs other than the lymph nodes, Waldeyer's ring, and spleen $)^{11}$ without or with only minor lymph node involvement were enrolled. Patients 
with lymphoblastic leukemia/lymphoma were excluded. Staging of lymphoma was done by clinical evaluation, computed tomography (CT) scans and bone marrow biopsy as in the standard recommendations and classified according to the modified Ann Arbor staging. ${ }^{11}$ Treatment of lymphomas were based on Thai national guidelines. ${ }^{12}$ Rituximab was given only in patients who indicated B-cell NHL who could access reimbursement by the government or self-pay during this period. The demographic data (age, sex), clinical signs and symptoms at presentation (GI tract, earnose-throat [ENT], hematological, nervous system, skin, urology, gynecology), stage of cancer, International Prognostic Index (IPI), ${ }^{13}$ pathological results, complete blood count $(\mathrm{CBC})$ results, treatment modalities (chemotherapy, radiation therapy [RT], and surgery), response according to Lugano Classification $^{11}$ (complete response [CR], partial response [PR], stable disease [SD], and progressive disease [PD]), and survival outcomes were obtained from the medical records. This study was approved by the Institutional Research Committee of the Faculty of Medicine, Chiang Mai University and was conducted in accordance with the Declaration of Helsinki.

\section{Statistical analysis}

Data concerning clinical presentations, laboratory, histology, stage, IPI, treatment, and causes of death were presented as descriptive analysis. Dichotomous variables were presented as percentage or ratio. Continuous variables were presented as mean \pm standard deviation (SD) or median (range). Overall survival was defined as the time from diagnosis to death from any cause or the last follow-up was analyzed using the Kaplan-Meier Method. Factors affecting OS were analyzed by univariate and multivariable methods using Cox proportional hazard model. SPSS version 23.0 was used for data analysis.

\section{Results}

\section{Clinical manifestations}

There were 104 patients with pENL enrolled onto this study with 57 of the patients being male (54.8\%) as shown in Table 1. The median age of the patients was 63 years (range 32-93). The majority of patients $(41.3 \%)$ had GI tract involvement followed by ENT (34.6\%), skin (6.7\%), and CNS (3.8\%). B-symptoms presented in $46.2 \%$ of patients. Mean hemoglobin was $12 \pm 1.9 \mathrm{~g} / \mathrm{dL}$ and mean $\mathrm{LDH}$ was $167 \pm 88$
U/L (normal range 135-225) with 17 patients $(16.3 \%)$ having an LDH above the normal upper limit. Thirteen patients $(12.3 \%)$ had bulky disease (tumor more than $10 \mathrm{~cm}$ ). ${ }^{11}$ The majority of patients presented with early stages of the disease (stage I 20.2\% and stage II 54.8\%) and low to low-intermediate IPI $(20.2 \%, 58.7 \%$, and $20.2 \%$ had score 0,1 , and 2 , respectively).

Regarding clinical presentations in patients with GI tract involvement, abdominal pain was the most common symptom (33 patients, 76\%) followed by GI hemorrhage and abdominal mass. The stomach was the most common site of involvement (55\%). In the case of ENT presentation, epistaxis and nasal congestion were the most common symptoms (7 patients each, 19\%) and the nasal cavity was the most common site of tissue diagnosis $(36 \%)$. Other ENT patients presented with a sore throat, mass in oral

Table 1. Patient characteristics $(\mathrm{N}=104)$.

\begin{tabular}{|c|c|c|}
\hline \multicolumn{3}{|c|}{ Characteristics } \\
\hline Age (years) & Age, Median (range) & $63(32-93)$ \\
\hline Sex, N (\%) & Male & $57(54.8)$ \\
\hline Primary site, N (\%) & $\begin{array}{l}\text { Gastrointestinal tract } \\
\text { Ear nose throat } \\
\text { Skin } \\
\text { Central nervous system } \\
\text { Eye } \\
\text { Urological } \\
\text { Gynecological } \\
\text { Hematological } \\
\text { Other }\end{array}$ & $\begin{array}{l}43(41.3) \\
36(34.6) \\
7(6.7) \\
4(3.8) \\
3(2.9) \\
3(2.9) \\
1(1) \\
1(1) \\
6(5.8)\end{array}$ \\
\hline B symptoms & Present & $48(46.2)$ \\
\hline \multicolumn{3}{|c|}{ Histology } \\
\hline B-cell, N (\%) & $\begin{array}{l}\text { DLBCL } \\
\text { MALT } \\
\text { MALT with large cell transformation } \\
\text { Burkitt's lymphoma } \\
\text { FL }\end{array}$ & $\begin{array}{c}62(59.6) \\
16(15.4) \\
9(8.7) \\
2(1.9) \\
1(1)\end{array}$ \\
\hline T-cell, N (\%) & $\begin{array}{l}\text { PTCL NOS } \\
\text { ENKTL }\end{array}$ & $\begin{array}{c}12(11.5) \\
1(1)\end{array}$ \\
\hline Hodgkin, N (\%) & & $1(1)$ \\
\hline $\mathrm{CBC}$ Mean $\pm \mathrm{SD}$ & $\begin{array}{l}\text { Hemoglobin }(\mathrm{g} / \mathrm{dL}) \\
\text { WBC }\left(\text { cell/mm³ }{ }^{3}\right) \\
\text { Platelet }(\text { cell/.mm³) }\end{array}$ & $\begin{array}{c}12 \pm 1.9 \\
7341 \pm 3210 \\
315288 \pm 124658\end{array}$ \\
\hline LDH, N(\%) & Above upper normal limits & $17(16.3)$ \\
\hline Stage, N (\%) & $\begin{array}{l}\text { I } \\
\text { II } \\
\text { IV }\end{array}$ & $\begin{array}{l}21(20.2) \\
57(54.8) \\
26(25.0)\end{array}$ \\
\hline Tumor bulk, N (\%) & & $13(12.5)$ \\
\hline IPI, N (\%) & $\begin{array}{l}0 \\
1 \\
2 \\
3 \\
4 \\
5\end{array}$ & $\begin{array}{l}21(20.2) \\
61(58.7) \\
21(20.2) \\
1(0.9) \\
0(0) \\
0(0)\end{array}$ \\
\hline Bone marrow involvement, $\mathrm{N}(\%)$ & & $11(10.6)$ \\
\hline
\end{tabular}

DLBCL: diffuse large B-cell lymphoma; MALT: marginal zone lymphoma of mucosa-associated lymphoid tissue; PTCL NOS: peripheral T-cell lymphoma, not otherwise specified; ENKTL: extranodal NK/T cell lymphoma, nasal type; FL: follicular lymphoma; CBC: complete blood count; LDH: lactate dehydrogenase; IPI: International Prognostic Index cavity (tongue, gum, and palate), thyroid mass, and hoarseness of voice.

\section{Pathological aspect}

DLBCL was the most common morphological subtype (62 patients, 59.6\%), followed by marginal zone lymphoma of MALT (24\% with $8.7 \%$ having large cell transformation), and peripheral T-cell lymphoma (PTCL) (11.2\%). A biopsy was carried out in the affected organs in all patients. The association of histological subtypes and organ involvement is described in Table 2.

\section{Treatment and outcomes}

About half of the patients received chemotherapy alone (56 patients, 53.8\%), followed by chemotherapy and surgery (24 patients, $23.1 \%$ ), chemotherapy and RT (16 patients, $15.4 \%$ ), RT alone (4 patients, $3.8 \%$ ), combined chemotherapy, RT, and 
surgery ( 2 patients, $1.9 \%)$, surgery alone (1 patient, $0.96 \%)$, and palliative care (1 patient, $0.96 \%$ ). In the majority of the patients there was a measurable response with an overall response rate (ORR) of $91.3 \%$ (95 patients) with a CR rate of $78.8 \%$ (83 patients), and a PR rate of $12.5 \%$ (13 patients). Eight patients (7.7\%) had PD and 1 patient $(0.96 \%)$ had SD. A relapse in the disease occurred in 17 patients $(16.3 \%)$

With the median follow-up time of 163 months (range 0-351 months), seven patients $(6.7 \%$; 3 DLBCL and 4 PTCL) had died, the most common cause of death being progression of the disease (4 patients; $57.1 \%$ ). Other causes included heart failure, myocardial infarction, and septic shock (1 patient in each case; $14.2 \%$ ). The five-year survival rate was $71 \%$ and the median overall survival was 131 months (range 0-351 months) (Figure 1). Table 3 shows the survival of $\mathrm{pENL}$ patients related to the primary site. Patients with the primary cancer being ENT and GI tract lymphoma had a 5year OS of $71 \%$ and $92 \%$, respectively, whereas almost all patients with other primary sites had a $100 \%$ survival at 5 years. According to histological subtypes, $\mathrm{pENL}$ with DLBCL had a 5-year OS of $95 \%$ and the corresponding figure for PTCL was $56 \%$. Associated factors of mortality from the multivariable analysis were anemia $(\mathrm{Hb}$
$<7 \mathrm{~g} / \mathrm{dL})(\mathrm{P}=0.003)(95 \%$ CI 2.70-36.76), presence of B-symptoms $(\mathrm{P}=0.047)(95 \%$ CI 1.90-6.40), and LDH above upper normal limits ( $\mathrm{P}=0.013)$ (95\% CI 2.55-11.41). Other factors including age, primary site, histological subtype, stage, IPI, tumor bulk, and bone marrow involvement were not significantly associated with OS (Table 4).

\section{Discussion and Conclusions}

This study demonstrates variations in the presentation, histology, and treatment outcomes of pENL. The prevalence of pENL was not studied but a recent study by the Thai Lymphoma Study Group (TLSG)

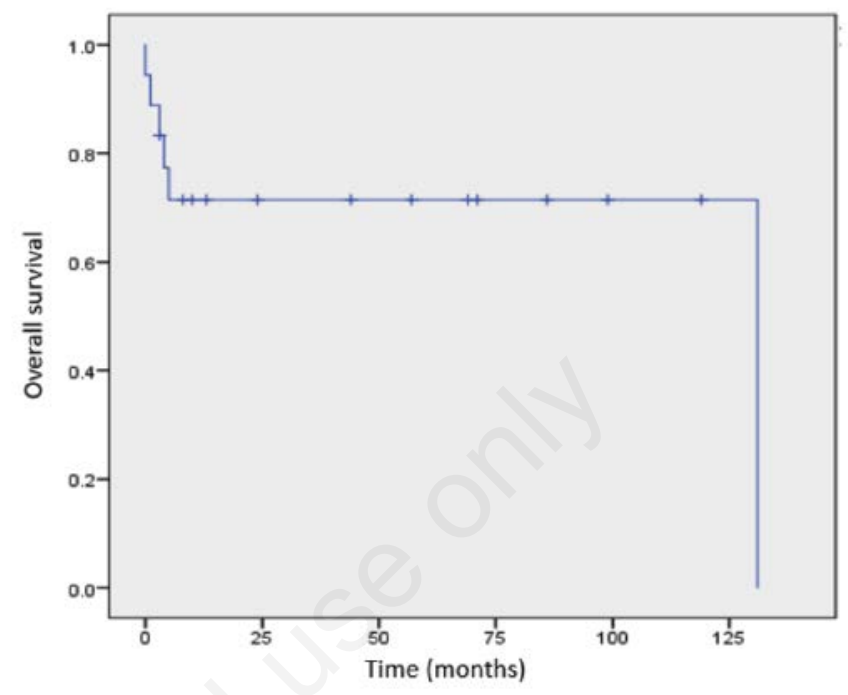

Figure 1. Kaplan-Meier survival curve showing overall survival in patients with primary extranodal lymphoma.

Table 2. Histological subtypes of primary extranodal lymphoma according to organ involvement.

\begin{tabular}{|c|c|c|}
\hline Primary organ & No. $(\%)$ & Histological subtype \\
\hline $\begin{array}{l}\text { Gastrointestinal tract } \\
\text { Stomach } \\
\text { Small bowel } \\
\text { Large bowel } \\
\text { Mesenteric mass }\end{array}$ & $\begin{array}{c}43(41.3) \\
24(23.1) \\
11(10.6) \\
4(3.8) \\
4(3.8)\end{array}$ & $\begin{array}{l}15 \text { DLBCL, } 6 \text { MALT, } 3 \text { MALT with large cell } \\
5 \text { DLBCL, } 3 \text { MALT, 1 MALT with large cell, } 1 \text { PTCL NOS, } 1 \text { Hodgkin } \\
2 \text { DLBCL, } 1 \text { MALT, } 1 \text { PTCL NOS } \\
3 \text { DLBCL, } 1 \text { Burkitt }\end{array}$ \\
\hline $\begin{array}{l}\text { Ear nose throat } \\
\text { Nasal cavity } \\
\text { Nasopharynx } \\
\text { Thyroid } \\
\text { Tongue } \\
\text { Parotid gland } \\
\text { Supraglottic mass } \\
\text { Gum } \\
\text { Maxillary sinus } \\
\text { Submandibular salivary gland } \\
\text { Soft palate } \\
\end{array}$ & $\begin{array}{l}36(34.6) \\
13(12.5) \\
6(5.8) \\
5(4.8) \\
5(4.8) \\
2(1.9) \\
1(0.9) \\
1(0.9) \\
1(0.9) \\
1(0.9) \\
1(0.9)\end{array}$ & $\begin{array}{l}6 \text { DLBCL, } 4 \text { PTCL NOS, } 2 \text { MALT, } 1 \text { ENKTL } \\
6 \text { DLBCL } \\
3 \text { MALT with large cell, } 2 \text { DLBCL } \\
3 \text { DLBCL, } 2 \text { PTCL NOS } \\
1 \text { DLBCL, } 1 \text { PTCL NOS } \\
1 \text { PTCL NOS } \\
1 \text { DLBCL } \\
1 \text { DLBCL } \\
1 \text { FL } \\
1 \text { DLBCL }\end{array}$ \\
\hline Skin & $7(6.7)$ & 3 DLBCL, 2 PTCL NOS, 1 MALT, 1 MALT with large cell \\
\hline CNS (Brain) & $4(3.8)$ & 4 DLBCL \\
\hline Eye (Orbit) & $3(2.9)$ & 3 MALT \\
\hline Urological (Testis) & $3(2.9)$ & 3 DLBCL \\
\hline Gynecological (Pelvic mass) & $1(0.9)$ & 1 Burkitt \\
\hline Hematological (Bone marrow) & $1(0.9)$ & 1 DLBCL \\
\hline $\begin{array}{l}\text { Other } \\
\text { Bone } \\
\text { Breast }\end{array}$ & $\begin{array}{l}6(5.8) \\
4(3.8) \\
2(1.9)\end{array}$ & $\begin{array}{l}4 \text { DLBCL } \\
1 \text { DLBCL, } 1 \text { MALT with large cell }\end{array}$ \\
\hline
\end{tabular}

DLBCL: diffuse large B-cell lymphoma; MALT: marginal zone lymphoma of mucosa-associated lymphoid tissue; MALT with large cell: marginal zone lymphoma of mucosa-associated lymphoid tissue with large cell transformation; PTCL NOS: peripheral T-cell lymphoma, not otherwise specified; ENKTL: extranodal NK/T cell lymphoma, nasal type; FL: follicular lymphoma. 
that collected data from 4056 patients in 13 major hospitals in Thailand showed that $49.6 \%$ had undergone diagnostic tissue biopsy from sites other than the lymph nodes and bone marrow but the percentage of pENL was not described. ${ }^{14}$ As a result, the prevalence of pENL in Thailand might be less than $50 \%$.

The most common organ involved with pENL was found to be the GI tract which accounted for about $40 \%$ and more than half of these patients had gastric involvement. This finding corresponded with other studies from the Netherlands (GI tract involvement of $45.7 \%),{ }^{6}$ Greece $(50.3 \%),{ }^{15}$ Kuwait (43\%), ${ }^{8}$ Taiwan (47.2\%), ${ }^{16}$ and Japan (30.4\%). ${ }^{17}$ Although bone marrow was the most common site of diagnosis of lymphoid neoplasms in Korea which included plasma cell myeloma and precursor lymphoblastic leukemia/lymphoma, the GI tract was also the subsequent most common extranodal organ involved $(30.4 \%$ and $18.3 \%$ of all lymphoid neoplasms, respectively). ${ }^{18}$ In contrast, the central nervous system (CNS) constituted the most common extranodal site in an Indian study $(29.7 \%)$, ahead of the GI tract $(25 \%)$ even there was no human immunodeficiency virus (HIV)-related CNS lymphoma in this cohort. ${ }^{9}$ The author suggested that it might have been identified more efficiently due to improvements in neuroimaging and stereotactic brain biopsy techniques. The result that the stomach was the most common organ in the GI tract involved in the lymphoma was consistent across many studies. ${ }^{6,8,9,15-17}$

The other site in which pENL was most commonly found were those associated with ENT. These comprised approximately $35 \%$ in our study. In a study in Southwest China, nose, sinuses, and Waldeyer's ring (including the tonsils, palate, nasopharynx, pharynx and base of tongue) were the sites most frequently involved in pENL $(44.1 \%$ compared with the GI tract, $22.3 \%){ }^{7}$ ENKTL $^{7,19}$ and orbital adnexal MALT lymphoma $^{14}$ had a higher prevalence in East Asia, which could be explained by the higher proportion of ENT involvement (23.2$44.1 \%)^{7,16,17}$ in these countries as well as in this study compared with Western countries $(11 \%-22.6 \%))^{6,15}$

Diffuse large B-cell lymphoma (DLBCL) was the most common histological subtype of pENL found in the current study $(59.6 \%)$, a similar finding to all other

Table 3. Five-year overall survival of patients related to the primary site.

\begin{tabular}{lccc} 
Primary site & Number $(\mathbf{N}=\mathbf{1 0 4})$ & Death $(\mathbf{N}=7)$ & 5-year OS (\%) \\
Gastrointestinal tract & 44 & 2 & 92 \\
Ear nose throat & 36 & 3 & 71 \\
\hline Skin & 7 & 0 & 100 \\
Central nervous system & 4 & 0 & 100 \\
\hline Eye & 3 & 0 & 100 \\
Urological & 3 & 0 & 100 \\
\hline Gynecological & 1 & 0 & 100 \\
Hematological & 1 & 1 & 0 \\
\hline Other & 6 & $1^{*}$ & 83 \\
\hline
\end{tabular}

*Primary site in the bone (humerus).

Table 4. Association of factors with mortality in patients with primary extranodal lymphoma.

\begin{tabular}{lcc} 
Factors & $95 \%$ CI & P-value \\
Age & $0.50-2.43$ & 0.373 \\
Primary site & $0.82-2.99$ & 0.254 \\
\hline Presence of B-symptom & $1.90-6.40$ & 0.047 \\
Histology & $0.42-1.45$ & 0.153 \\
\hline Low hemoglobin $(<7 \mathrm{~g} / \mathrm{dL})$ & $2.70-36.76$ & 0.003 \\
LDH above upper normal limit & $2.55-11.41$ & 0.013 \\
\hline Stage (III, IV) & $0.17-2.28$ & 0.352 \\
Bulky mass & $0.28-2.55$ & 0.592 \\
\hline IPI $(>2)$ & $0.26-1.52$ & 0.263 \\
Bone marrow involvement & $0.49-2.10$ & 0.554 \\
\hline Relapse & $0.70-1.90$ & 0.321 \\
\hline
\end{tabular}

LDH: lactate dehydrogenase; IPI: International Prognostic Index. cited studies $(40-71 \%) .^{6-9,15,17}$ MALT lymphoma was the second most prevalent $(15.4 \%)$ as it was in the studies from India $(13.2 \%),{ }^{9}$ Greece $(10.7 \%),{ }^{15}$ Korea $(31.1 \%),{ }^{18}$ and in a human T-cell leukemia virus type 1 nonendemic area in Japan $(13.3 \%) .{ }^{17}$ The corresponding figures were different among various countries including the Netherlands (CLL/SLL, 11\%), ${ }^{6}$ Kuwait (FL, 32\%), ${ }^{8}$ and China (ENKTL, 26.2\%). ${ }^{7}$ Thus, ENKTL in the current study (1\%) and in the TLSG cohort $(2.7 \%)$ did not have the same prevalence as in China and MALT lymphoma was less common than Korea. Compared with the recent large TLSG cohort from Thailand, DLBCL, FL, and MALT lymphoma accounted for the vast majority of lymphomas $(58.1 \%, 5.6 \%$, and $5.2 \%$, respectively) including both nodal and extranodal lymphomas. This might be explained by FL usually presenting as a nodal disease in contrast to MALT lymphoma. ${ }^{10}$ Other demographic data pertinent to $\mathrm{pENL}$ in the current study included a median age of 63 years with a slight male predominance (ratio 1.2: 1) which was comparable with the TLSG cohort (median age of 56 years with male to female ratio of 1.3: 1). However, pENL in Thai patients tended to occur at a younger age than it did in western countries which reported a median age of more than 65 years. ${ }^{6,15}$ In addition a study from India showed the mean age of pENL patients to be 43 years, even lower than our current study, as well as less than nodal NHL (58 years). ${ }^{9}$ No significant difference in the age of patients with pENL and nodal NHL was found in the Dutch study (65 and 67 years, respectively). ${ }^{6}$ This was found to be the opposite in the Japanese study (pENL had higher mean age of 61 years, $\mathrm{P}<0.001) .{ }^{17}$ The majority of $\mathrm{pENL}$ patients in this study presented as early stages of the disease (stage I-II) and had low to low-intermediate IPI. These findings are similar to other studies into pENL carried out in both Asian $8,9,16,17$ and western countries. ${ }^{6}$

The differences in the epidemiology of pENL in each study may be due to both genetic and environmental factors. Genome-wide association studies have identified many single nucleotide polymorphisms that related with specific subtypes of lymphoma in various populations, ${ }^{20}$ but the data from Thailand is lacking. MALT lymphoma is well recognized as an infectious-related lymphoma. The higher proportion of ocular adnexal MALT lymphoma found in comparison with gastric MALT lymphoma in this study was similar to that found in a previous TLSG study. ${ }^{14}$ The prevalence of Chlamydia psittacosis and Helicobacter pylori infection in each coun- 
try may well affect the prevalence of MALT lymphoma in these two locations, ${ }^{2,4}$ but the studies in Thailand about this aspect are still limited.

Analysis of the treatment outcomes showed a favorable response rate (CR rate of $78.8 \%$ ) leading to a five-year OS of $71 \%$ with a median OS of 131 months. This may be explained by the majority of patients being in early stages of the disease $(75 \%)$ with low to low-intermediate IPI (99.1\%). In the study there were variations in histological subtypes of pENL and modalities of treatment as well as inaccessibility to rituximab, ${ }^{21}$ which could influence the interpretation and cause difficulties in making direct comparison to other studies into $\mathrm{pENL}$ and nodal lymphoma. In addition to this point, there were conflicting data regarding the OS of pENL and nodal lymphoma, $6,8,17$ partially due to the different definition of pENL. ${ }^{5}$ In this current study that had a relatively small number of patients, anemia, B-symptoms, and high LDH were associated with OS. These factors were also found to be the prognostic factors in some subtypes of lymphoma including DLBCL and MALT lymphoma. ${ }^{11,13,22,23}$

The limitation of this study was related to the retrospective nature which might have led to incomplete data collection and selection bias. In addition, it represented information regarding $\mathrm{pENL}$ from a single institution with a limited number of patients. As a result, the subgroup analysis of outcomes according to histological subtypes and primary extranodal organs might be not accurately interpreted. Nevertheless, the current study provided real world data regarding $\mathrm{pENL}$ in Thailand. A larger prospective multi-center study comparing information about $\mathrm{pENL}$ with details about primary nodal lymphoma is warranted.

In conclusion, lymphoma can have various extranodal presentations. The GI tract, in particular the stomach, was the most common location of $\mathrm{pENL}$ treated in Chiang Mai University Hospital. DLBCL was the most common subtype of $\mathrm{pENL}$ found followed by MALT lymphoma.

\section{References}

1. Jaffe ES, Swerdlow SH, Vardiman JW. Haematopoietic and lymphoid malignancies. In: Stewart BW, Wild CP, editors. World Cancer Report 2014. Lyon:
IARC. 2014

2. Jaffe ES, Campo E, Harris NL, et al. Introduction and overview of the classification of lymphoid neoplasms. In: Swerdlow SH, Campo E, Harris NL, et al, eds. World Health Organization Classification of Tumours of Haematopoietic and Lymphoid Tissues. Lyon, France: IARC; 2017 Revised Edition.

3. Forman D, Ferlay J. The global and regional burden of cancer. In: Stewart BW, Wild CP, editors (2014). World Cancer Report 2014. Lyon: IARC; 2014.

4. Armitage JO, Gascoyne RD, Lunning MA, et al. Non-Hodgkin lymphoma. Lancet 2017;390:298-310.

5. Zucca E. Extranodal lymphoma: a reappraisal. Ann Oncol 2008;19:iv77-80.

6. Krol ADG, le Cessie S, Snijder S, et al. Primary extranodal non-Hodgkin's lymphoma (NHL): the impact of alternative definitions tested in the Comprehensive Cancer Centre West population-based NHL registry. Ann Oncol 2003;14:131-9.

7. Yang QP, Zhang WY, Yu JB, et al. Subtype distribution of lymphomas in Southwest China: Analysis of 6,382 cases using WHO classification in a single institution. Diag Pathol 2011;6:77.

8. Salem H, Reem M, Kamlesh P. Extranodal lymphoma: a comparative study. Hematology 2008;13:163-9.

9. Padhi S, Paul T, Challa S, et al. Primary extranodal non Hodgkin lymphoma: A 5 year retrospective analysis. Asian Pac J Cancer Prev 2012;13:4889-95.

10. Swerdlow SH, Campo E, Harris NL, et al, eds. World Health Organization Classification of Tumours of Haematopoietic and Lymphoid Tissues. Lyon, France: IARC; 2008.

11. Cheson BD, Fisher RI, Barrington SF, et al. Recommendations for initial evaluation, staging, and response assessment of Hodgkin and non-Hodgkin lymphoma: The Lugano Classification. J Clin Oncol 2014;32:3059-67.

12. Seksan P, Prayoonwiwat W, Intragumtornchai $\mathrm{T}$, eds. Guideline for treatment of hematologic diseases in Thailand 2011. Bangkok, Thailand: Num Uksorn Publishing; 2011.

13. The International Non-Hodgkin's Lymphoma Prognostic Factors Project. A predictive model for aggressive nonHodgkin's lymphoma. N Engl J Med
1993;329:987-94.

14. Intragumtornchai $T$, Bunworasate $U$, Wudhikarn K, et al. Non-Hodgkin lymphoma in South East Asia: An analysis of the histopathology, clinical features, and survival from Thailand. Hematol Oncol 2017;1-9.

15. Economopoulos T, Papageorgiou S, Dimopoulos MA, et al. Non-Hodgkin's lymphomas in Greece according to the WHO classification of lymphoid neoplasms. Acta Haematol 2005;113:97103.

16. Chen WL, Tsai WC, Chao TY, et al. The clinicopathological analysis of 303 cases with malignant lymphoma classified according to the World Health Organization classification system in a single institute of Taiwan. Ann Hematol 2010;89:553-62.

17. Fujita A, Tomita N, Fujita $H$, et al. Features of primary extranodal lymphoma in Kanagawa, a human T-cell leukemia virus type 1 nonendemic area in Japan. Med Oncol 2009;26:49-54.

18. Yoon SO, Suh C, Lee DH, et al. Distribution of lymphoid neoplasms in the Republic of Korea: Analysis of 5318 cases according to the World Health Organization classification. Am J Hematol 2010;85:760-4.

19. Yamaguchi M, Suzuki R, Oguchi M. Advances in the treatment of extranodal NK/T-cell lymphoma, nasal type. Blood 2018;131:2528-40.

20. Cerhan JR, Slager SL. Familial predisposition and genetic risk factors for lymphoma. Blood 2015;126:2265-73.

21. Intragumtornchai $T$, Bunworasate $U$, Siritanaratkul N, et al. Inferior progression-free survival for Thai patients with diff use large B-cell lymphoma treated under Universal Coverage Scheme: the impact of rituximab inaccessibility. Leuk Lymphoma 2013;54:83-9.

22. Solal-Celigny P, Roy P, Colombat P, et al. Follicular lymphoma international prognostic index. Blood 2004;104: 1258-65.

23. Thieblemont C,Cascione L, Conconi A, et al. A MALT lymphoma prognostic index. Blood. 2017;130:1409-17. 